\title{
Load carrying capacity of castellated I-beam in the elastoplastic formulation problem
}

\author{
Oleg Goryachevskiy* \\ Moscow State University of Civil Engineering, Yaroslavskoe shosse, 26, Moscow, 129337, Russia
}

\begin{abstract}
Developed a method for calculating the load carrying capacity of castellated I-beam with ideal elastoplastic material model in ANSYS Mechanical. The method verified in the test problem of bending a rectangular beam. The ultimate load and ratio of ultimate load to limited load for two different I-beams were calculated. The method can be used for other steel construction.
\end{abstract}

\section{Introduction}

Existing analytical method for calculating strength and rigidity of castellated I-beams are far from perfect [1]. The reason for this is the complexity of the geometric shape of the castellated I-beams. Thus, the rigidity, strength, stability and other characteristics of castellated I-beams can be investigated with sufficient accuracy only by experiment and numerical methods. In this study, the strength of castellated I-beam in an elastoplastic formulation is analyzed using the finite element method (implemented in ANSYS Mechanical software).

As is known, the appearance of plastic strain along the edges of a section does not mean a loss of load carrying capacity. It is necessary to significantly increase a load to destroy the steel beam. For example, when the beam of the rectangular section is bent $-Q_{u}=1.5 Q_{y}$, where $Q_{\mathrm{u}}$ - ultimate load, $Q_{\mathrm{y}}-$ limit load at which the longitudinal stress equal yield stress in the upper and lower section faces of the section [2].

It is important to know what margin of safety $k=Q_{\mathrm{u}} / Q_{\mathrm{y}}$ still has the castellated I-beam, after plastic strain have already begun in its flanges. For normal I-beams, $k=1.5$ 1.8 (ideal elastoplastic material). The angles of the holes in web of the castellated I-beams are stress concentrators. Even at low load, plastic strain appears in them. But the region of plastic strain is small and begins to significant increase only when current load near to ultimate load [3]. The question arises, do the stress concentrators reduce the safety margin of castellated I-beams in comparison with normal I-beam?

To answer this question, a method for calculating the ultimate load $Q_{\mathrm{u}}$ in ANSYS Mechanical was developed. The ideal elastoplastic material was considered. The developed method was verified in the test problem and applied to the calculation of castellated Ibeams.

\footnotetext{
*Corresponding author: osgoryachevskij@mail.ru
} 


\section{Method of calculate ultimate load}

If the material is elastoplastic, standard means of ANSYS Mechanical do not allow to determine the moment of destruction of the structure, and hence the load carrying capacity, because the process of destruction is accompanied by the development of infinitely large displacements of the model nodes.

Nevertheless, ANSYS Mechanical has instruments, a certain combination of which allows to solve the problem of bending in ideal elastoplastic formulation problem.

The author proposes the following method, the effectiveness and accuracy of which is confirmed in a next section.

\section{$\underline{1 \text { step }}$}

A finite element (FE) model of castellated I-beam with a linear elastic material is created. Boundary conditions and load $Q_{0}$ are defined. A linear static analysis is performed. In the postprocessor, the limit load $Q_{\mathrm{y}}$ is calculate by von Mises yield criterion. In view of the linearity of the problem:

$$
Q_{\mathrm{y}}=Q_{0} \cdot \sigma_{\mathrm{y}} / \sigma_{\max },
$$

where $\sigma_{\mathrm{y}}$ - yield strength of steel, $\sigma_{\max }-$ maximum von Mises stress.

$$
\underline{2 \text { step }}
$$

The plastic properties of the material are added in the existing FE model. As the material model, we select Bilinear Isotropic Hardening or Bilinear Kinematic Hardening (yield stress equal $\sigma_{\mathrm{y}}$ and tangent modulus equal 0 ). A load $\alpha Q_{\mathrm{y}}$ is applied. The coefficient $\alpha$ is chosen so that the load carrying capacity of the structures is guaranteed to be exhausted, but not too large, because this will increase the calculation time. In the solver settings, all parameters should be left by default. Nonlinear static analysis is performed.

A feature of the nonlinear solver ANSYS Mechanical is that the load is incremented step by step, so you can track at what portion of the load the solution is not converge. It is obvious that under the load $\alpha Q_{\mathrm{y}}$ the solution can not converge. Therefore, as a result of this calculation, we calculate in the first approximation the ultimate load

$$
Q_{\mathrm{I}}=t \alpha Q_{\mathrm{y}},
$$

where $t \in(0,1)$ - the time of the last step.

The value $Q_{\mathrm{I}}$ gives an approximate estimate of the load carrying capacity of the beam since criterion for stopping the solve in ANSYS Mechanical is the excess of any node displacement of certain value (default is $1.0 \cdot 10^{6}$ )

The step in which plastic strain appear at all points of the section does not coincide with the step at which the critical displacement for the solver. It is obvious that $Q_{\mathrm{I}}$ will give an overestimated value of the ultimate load, if a unit of length is meter and the criterion for stopping the solve is not changed.

To refine the value of the ultimate load $Q_{\mathrm{I}}$, it is required to investigate the change in the plastic strain distribution pattern as a function of load in the neighbor of ultimate load $Q_{\mathrm{I}}$.

\section{$\underline{3 \text { step }}$}

A repeated nonlinear static analyses is performed with the adjustment of the solution steps. On the linear region of the solution $\left[Q(\right.$ time $\left.) \leq Q_{\mathrm{y}}\right]$, it is expedient to single out 1 step, which will shorten the total calculation time. The nonlinear region of the solution $\left[Q_{\mathrm{y}} \leq Q(\right.$ time $\left.) \leq Q_{\mathrm{I}}\right]$ should be divided into 2 parts.

On the first part $\left[Q_{\mathrm{y}}<Q(\right.$ time $\left.) \leq Q_{\mathrm{I}}-f\right]$, when it is still far enough up to the moment of destruction, it is necessary to allocate a moderate number of steps so that plastic strain do not spread faster than one element on one step. 
For the near-critical second region $\left[Q_{\mathrm{I}}-f<Q(\right.$ time $\left.) \leq Q_{\mathrm{I}}\right]$, large number of steps should be chosen to obtain the necessary accuracy in determining the moment of failure. Further, plastic strain and von Mises stress analyzed at different steps of the solution. Based on the results of the analysis, a conclusion is made about the value of the ultimate load in the second approximation $Q_{\mathrm{II}}$.

\section{Verification of the method}

In order to verify the developed method, we solve the classical problem of the ideal elastoplastic bending of a beam of rectangular cross section.

Consider a rectangular steel beam, supported at its ends and loaded by a uniformly distributed load Q. As a diagram $\sigma-\varepsilon$, we began to use bilinear diagram, taking elasticity modulus $E=200 \mathrm{GPa}$ and yield strength $\sigma_{\mathrm{y}}=300 \mathrm{MPa}$. (Fig. 1).

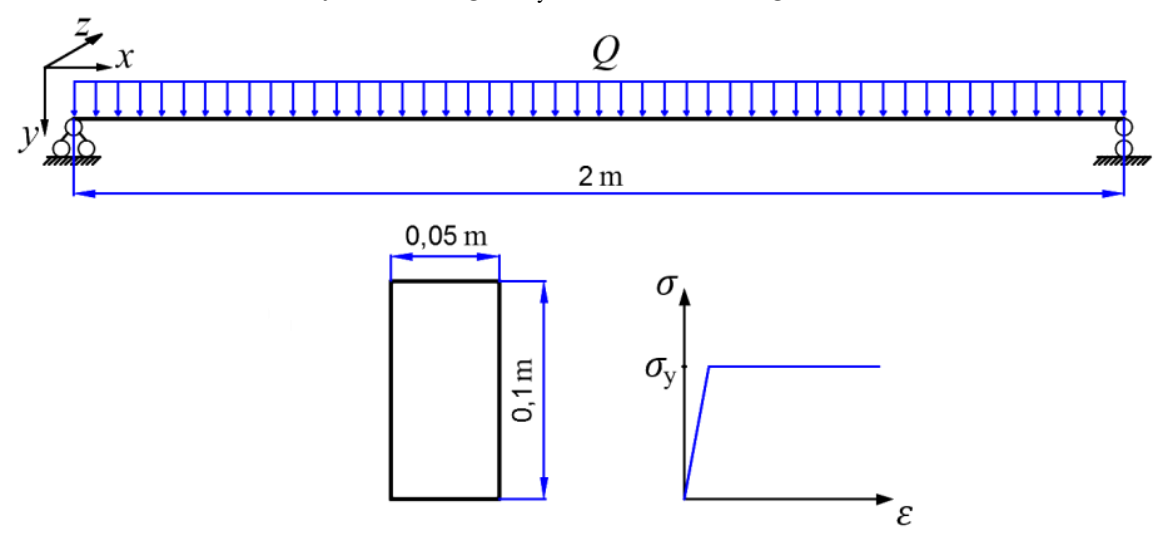

Fig. 1. The beam design, geometric parameters and diagram $\sigma-\varepsilon$.

The exact analytical solution of this problem $Q_{\mathrm{u}}=2 b h \sigma_{\mathrm{y}} / L^{2}=75000 \mathrm{~N} / \mathrm{m}$ [4], where $b-$ the width of the section, $h$ - the height of the section, $L$ - the length of the beam.

We construct two FE models of the given problem (Fig. 2, Table 1) in the ANSYS Mechanical, differing in the type of finite elements. We calculate the ultimate load according to the above method (Table 2).

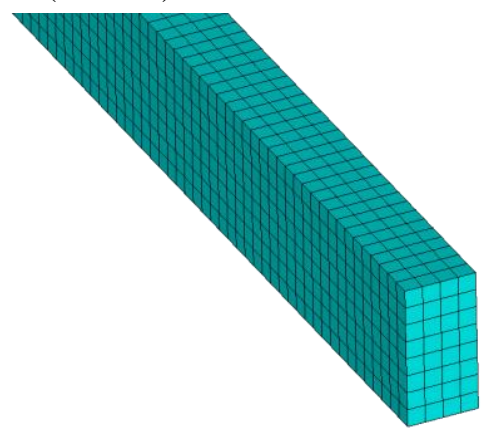

Fig. 2. The finite element model of the beam.

Table 1. Parameters of FE models of beams.

\begin{tabular}{|c|c|c|}
\hline Type of finite elements & Number of elements & Number of nodes \\
\hline Linear Solid185 & 5120 & 7245 \\
\hline Quadratic Solid186 & 5120 & 26681 \\
\hline
\end{tabular}


The analytical solution of this problem is based on the plasticity criterion $\sigma_{\mathrm{x}}=\sigma_{\mathrm{y}}$, where $\sigma_{\mathrm{x}}-$ longitudinal stress. In ANSYS Mechanical we used a model of Bilinear Isotropic Hardening, in which the criterion of plasticity is the von Mises criterion:

$$
\left\{\left[\left(\sigma_{1}-\sigma_{2}\right)^{2}+\left(\sigma_{2}-\sigma_{3}\right)^{2}+\left(\sigma_{3}-\sigma_{1}\right)^{2}\right] / 2\right\}^{1 / 2}=\sigma_{\mathrm{y}},
$$

where $\sigma_{1}, \sigma_{2}, \sigma_{3}$ - principal stresses.

Both criteria are almost equivalent in this problem, since all components of the stress tensor in the middle of the span are several orders of magnitude smaller than $\sigma_{\mathrm{x}}$. Fig. 3.

The ultimate load in the second approximation $Q_{\text {II }}$ was calculate from the graphs in

Table 2. Results of calculations of ultimate load for beam.

\begin{tabular}{|c|c|c|c|}
\hline \multirow{2}{*}{$\begin{array}{c}\text { No. } \\
\text { step }\end{array}$} & \multirow{2}{*}{ Result } & Solid185 & Number of nodes \\
\cline { 3 - 4 } & & 51034 & 49967 \\
\hline 1 & $Q_{\mathrm{y}}, \mathrm{N} / \mathrm{m}$ & $\begin{array}{c}76206 \\
75365\end{array}$ \\
\hline 2 & $Q_{\mathrm{I}}, \mathrm{N} / \mathrm{m}$ & $101,6 \%$ of the analytical solution & $101,6 \%$ of the analytical solution \\
\hline 3 & $Q_{\mathrm{II}}, \mathrm{N} / \mathrm{m}$ & $\begin{array}{c}75837 \\
101,6 \% \text { of the analytical solution }\end{array}$ & $\begin{array}{c}75150 \\
101,6 \% \text { of the analytical solution }\end{array}$ \\
\hline
\end{tabular}
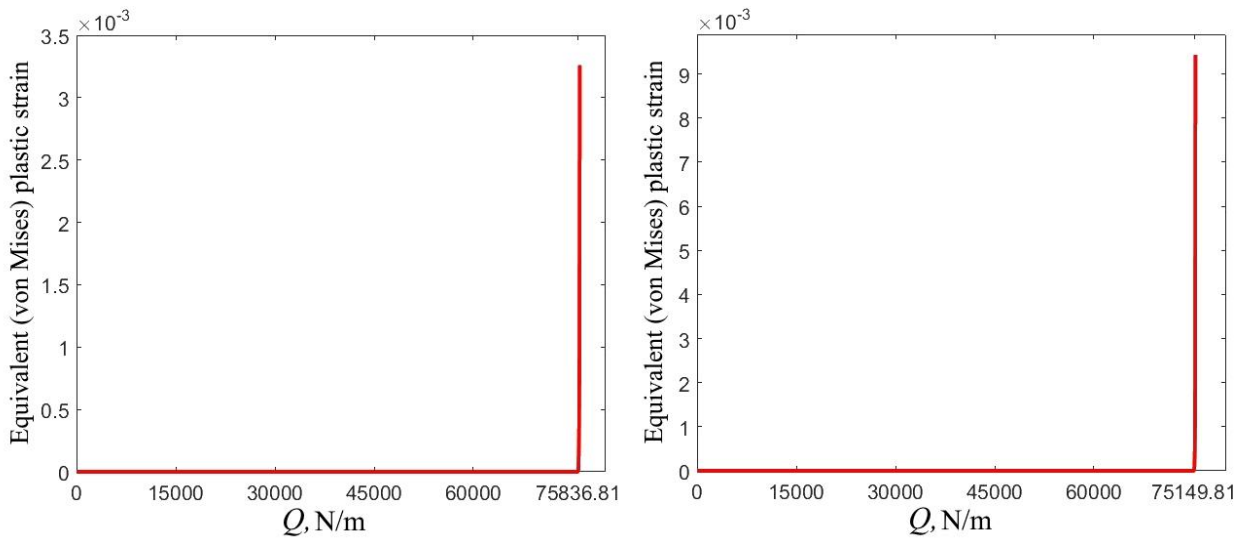

Fig. 3. Plot of the strain from load $Q($ time $)$ in the middle of center section.

The results of the analytical solution and numerical solution by the developed method are very similar. Sufficient for practical purposes accuracy is achieved after the second step of the developed method.

Thus, the efficiency and accuracy of the developed method is confirmed.

\section{Calculation of ultimate load for castellated I-beam}

The above method was used to determine the maximum load of hexagonal castellated Ibeam. As example, two beams (Table 3), made of hot rolled I-beams I30 (GOST8239-89) of steel St3sp, loaded with a uniformly distributed load, were taken. The loading scheme and boundary conditions are assumed to be the same as in the test problem (Fig. 1).

As a diagram $\sigma-\varepsilon$ a bilinear diagram was used, elastic modulus $E=200 \mathrm{GPa}$, yield strength $\sigma_{\mathrm{y}}=245 \mathrm{MPa}$. 
The results were compared with the maximum loads calculated according to SP 16.13330.2011 «Steel structures» $\left(R_{\mathrm{y}}=245 \mathrm{MPa}, R_{\mathrm{u}}=370 \mathrm{MPa}, \gamma_{\mathrm{c}}=1\right)$.

The geometric parameters of the castellated I-beams, the number of finite elements and nodes are shown in Table 3. The geometry model and fragment of the FE model are shown in Fig. 4. The symmetry condition was taken into account in order to reduce the number of finite elements [5-9].

The ultimate load in the second approximation $Q_{\mathrm{II}}$ is calculated on the basis of the analysis of the propagation of the region of plastic strains as a function of the value of the load.

The stress and strain distribution patterns at the moment of failure for both castellated Ibeam is shown in Fig. 5-7.

Table 3. Parameters of models of castellated I-beam.

\begin{tabular}{|c|c|c|c|c|c|}
\hline $\begin{array}{c}\text { Model } \\
\text { No. }\end{array}$ & $\begin{array}{c}\text { Length, } \\
\text { m }\end{array}$ & $\begin{array}{c}\text { Number } \\
\text { of holes }\end{array}$ & Geometric parameters & $\begin{array}{c}\text { Number finite } \\
\text { elements/nodes }\end{array}$ \\
\hline 1 & 3 & 6 & & & \\
\hline
\end{tabular}

Duration of calculating $Q_{\mathrm{I}}$ equal about $1 \mathrm{~min}$ and $Q_{\mathrm{II}}-$ about $5 \mathrm{~min}$ (CPU - Intel Core i7-6700K 4.00GHz).

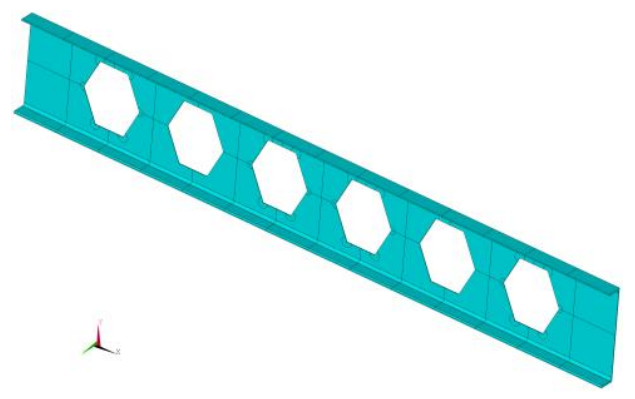

a)

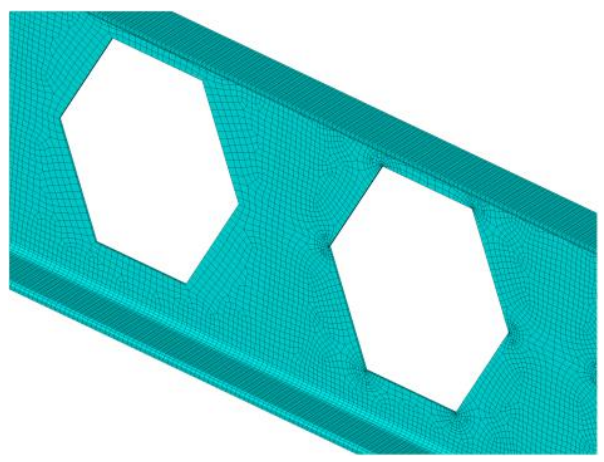

b)

Fig. 4. The geometric model No.1 (a) and fragment of FE model No.1 (b). 
Table 4. Results of calculations of ultimate load for models No.1 and №2.

\begin{tabular}{|c|c|c|}
\hline \multirow{2}{*}{ Load } & \multicolumn{2}{|c|}{ Model No. } \\
\hline & 1 & 2 \\
\hline $\begin{array}{c}Q_{\mathrm{yc}} \text {, the load corresponding to the appearance of plastic strain } \\
\text { in the corners of holes, } \mathrm{N} / \mathrm{m}\end{array}$ & 20204 & 8078 \\
\hline $\begin{array}{c}Q_{\mathrm{y}} \text {, the load corresponding to the appearance of plastic strain in } \\
\text { the flanges, } \mathrm{N} / \mathrm{m}\end{array}$ & 93363 & 34922 \\
\hline$Q_{\mathrm{I}}$, the ultimate load in the first approximation, $\mathrm{N} / \mathrm{m}$ & 112810 & 42058 \\
\hline$Q_{\text {II, }}$ the ultimate load in the second approximation, $\mathrm{N} / \mathrm{m}$ & 110032 & 41378 \\
\hline
\end{tabular}

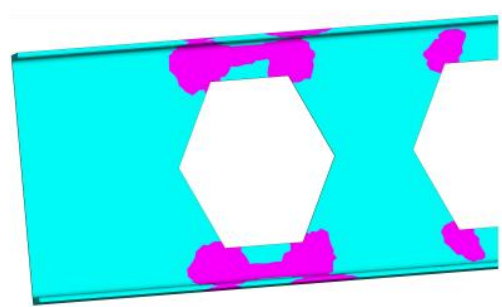

a)

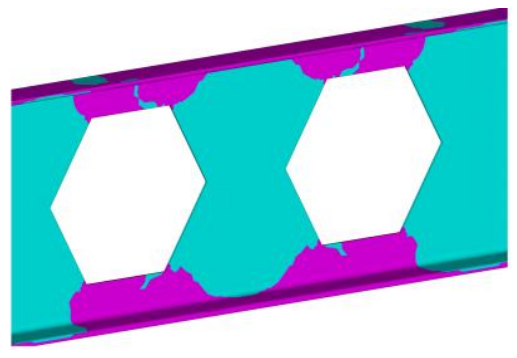

b)

Fig. 5. The region of plastic strain on the deformed scheme at the time of failure of castellated I-beam No. 1 (a) and No.2 (b).


Fig. 6. The von Mises stress (MPa) distribution pattern for model No.1.
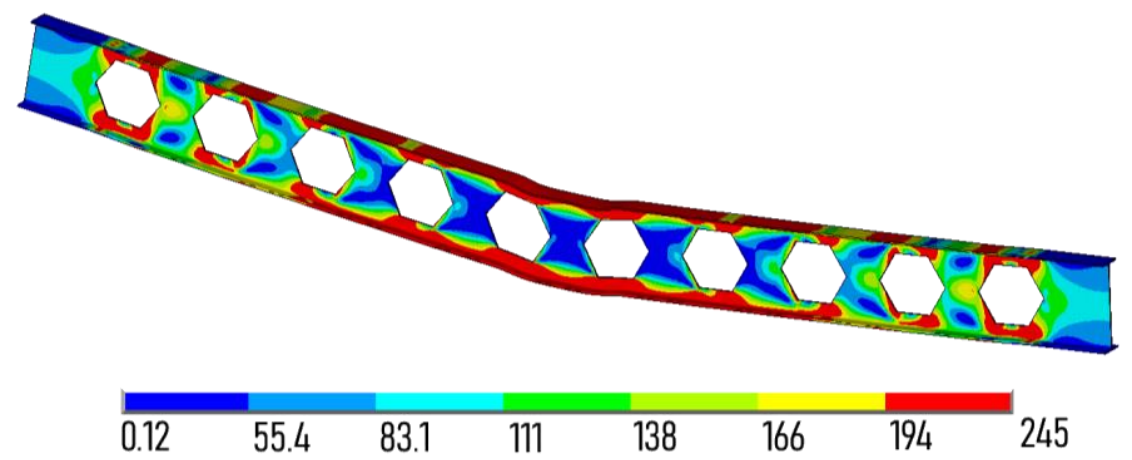

Fig. 7. The von Mises stress (MPa) distribution pattern for model No.2. 
The ratio characterizes $k=Q_{\mathrm{II}} / Q_{\mathrm{y}}$ the margin of safety of the beams in relation to the state at which plastic strain appear in the flanges. For both calculated models of castellated I-beams $k \approx 1.18$.

Failure mechanisms differ in the model No.1 and model No.2. The short beam No.1 collapse near the support, and the long beam No.2 collapses in the middle of the span.

\section{Conclusion}

The method for calculated the load carrying capacity of castellated I-beam in ideal elastoplastic bending in ANSYS Mechanical has been developed. The accuracy of the method is confirmed by a test problem. Sufficient accuracy for practical purposes is achieved already when calculating the ultimate load in the first approximation. Calculating ultimate load in the second approximation may take a long time if the problem of large.

The margin of safety $k$ of castellated I-beam is not less than that of rolled I-beam. This suggests that stress concentrators in the corners of the holes do not cause a dangerous spread of plastic strain.

\section{References}

1. SP 16.13330.2011. (2011)

2. O.S. Goryachevskiy, V.A. Belov. Pod.-transp. del, 1, 8-10 (2017)

3. V.A. Belov, K. Krul'. Modelirovanie i raschet metallicheskih konstrukciy zdaniy i sooruzheniy (2012).

4. Yu. N. Rabotnov. Mekhanika deformiruemogo tvyordogo tela. 2 izd, 712 (1988)

5. V. Belov, O. Goryachevskij. MATEC W. of C., 00017 (2017)

6. M.R. Soltani, A. Bouchaïr, M. Mimoune. J. of Const. St. Res., 70, 101-114 (2012)

7. S. Gholizadeh, A. Pirmoz, R. Attarnejad. J. of Const. St. Res., 67, 770-779 (2011)

8. R. Frans, H. Parung, D. Sandy, S. Tonapa. Pr. Eng., 171, 781-788 (2017)

9. O.S. Goryachevskiy. Pod.-trans., stroit., dorozh., putev. mash. i robot. komp. 138-139 (2016). 